\title{
A Reliability-Based Comparison of EC3 \& SANS 10162-1
}

\author{
Gerald Musa Nkosi (1), Jeffery Mahachi (2), Stephen Adeyemi Alabi (3) \\ Department of Civil Engineering, University of Johannesburg, Johannesburg, South Africa. \\ ${ }^{1}$ geraldm.nkosi@gmail.com; ${ }^{2}$ jmahachi@uj.ac.za; ${ }^{3}$ aalabi@uj.ac.za
}

\begin{abstract}
Wind and seismic activity effects are described in SANS 10160 (2018) [13]; however, these loading conditions' scope and depth are limited. Typically, South African practicing engineers refer to other international design standards when seeking information that is not described in the current national standards. It is essential to understand that these international standards cannot be used without considering local conditions. In this study the authors compare Eurocode 3 and SANS 10162-1 (the steel standards) using reliability principles to determine if the adoption or adaption of the Eurocode is possible. The reliability analysis presented in this paper assessed the material resistance reliability of a member in bending and a member under axial compression. The resulting reliability indices of the study, from a Monte Carlo Simulation, were compared to their respective target reliability index values. The beam and column, for their respective steel design standards, achieved minimum reliability index levels, with the column generally resulting in higher reliability indices. The authors also concluded that the SANS 10162-1 standard is usually consistent with European practice, which is confirmed by similar reliability levels. However, the differences in reliability levels show the effect and significance of local differences (e.g., construction methods, design loads, local conditions). Finally, the authors concluded that an adaption of the Eurocode's relevant sections is possible without a need for further calibration.
\end{abstract}

Keywords: Eurocode 3, SANS 10162-1, Probability of failure, Reliability, Comparison, Steel design.

\section{Introduction}

The tallest building in South Africa, the Leonardo stands at $227.91 \mathrm{~m}$ tall. However, it has been acknowledged that local authorities' in-charge of structures do not have the capacity to review the structural designs. Mallin (2019) [10] indicated that recent developments in structural advances such as taller buildings and larger spans have exposed the limitations of the current South African design standards (precisely dynamic and wind aspects).

The realization that the SANS 10160 (2011) scope was limited (Mallin, 2019) [10] led to updating three parts of the loading standard. Part 1 is based on structural design, and parts 3 and 4 cover wind and seismic actions, respectively. In the revised SANS 10160 (2018) [13] standard, wind and seismic activity effects have been modified; however, these loading conditions' scope and depth are still limited (Mallin, 2019) [10]. Infrastructure is a crucial component in economic growth, competitiveness, and international trade. Therefore, a developing nation such as South Africa must continue to compete globally by improving and adding to its infrastructure.

The standard that is currently being used in Europe for structural steel is EN 1993 (2005), which is used together with the "head code" EN 1990 (2002) [5] that provides the safety-related material independent requirements for the basic design of structures. The compilation of a design standard requires vast resources. A country undergoing a challenging economic phase seems better suited to adopt the Eurocode or better align the local standards to the harmonized Eurocode. South Africa has already begun adopting the Eurocode in concrete; however, in steel, the same standard (SANS 10162-1 (SANS10162-1, 2005)) [14] is still used. The Eurocode represents a standard formulated on the principles of reliability and demonstrates the utility of reliability principles. The South African loading standard (SANS10160, 2018) [13] follows the principles of partial factor limit state design, and the design procedures depend on unwavering quality standards. This ensures that appropriate levels of safe and sound structures can be achieved. To recognize the limitations of the current South African steel standard, this paper presents a reliability-based comparison of SANS 10162-1 with EC3 (EC3, 2002) [2]. Structural reliability provides a genuine basis for the development of standards identified by Retief et al. (2011) [12] and the further development of structural design standards allowing for consistency, harmonization, and calibration to local environmental conditions. 


\section{Reliability Modelling \\ 2.1. Functional Reliability Principle}

Reliability theory is the formulation of design principles, comparisons of the load factors, load combinations, and material resistance factors. The primary objective of reliability theory is to assess the probability of failure Pf, which can be expressed in the form of the following equation:

$$
P_{f}=P(E<R)
$$

where $\mathrm{E}$ is the load effect, and $\mathrm{R}$ is the resistance. Both $\mathrm{E}$ and $\mathrm{R}$ are generally random and are therefore associated with uncertainties. The limit-state is a state of a structure and can be classified as satisfactory or unsatisfactory, the conditions that separate the two is called limit state. However, it is non-linear, numerous iterations would have to be implemented, and as the results begin to converge, the probability of failure converges to an accurate value. This is achieved through a Monte Carlo Simulation, which yields more accurate $\beta$ T values than, for example, the first order and second-order approximation methods known as FORM or SORM. For small problems, FORM and SORM have been proved to be proficient; however, with an increase in the number of random variables, the problems become more complicated and require additional computational effort, which is better solved by the Monte Carlo Simulation (MCS.).

The Monte Carlo Simulation is an iterative process where the limit state function is evaluated. It is based on the number of iterations, and the probability of failure can be determined from Equation 2.

$$
P_{f}=\frac{1}{N} \sum_{i=1}^{N} I\left(x_{i}\right)
$$

where $x i=x_{1}, x_{2}, x_{3} \ldots x_{N}, I\left(x_{i}\right)$ is a function that indicates the successful or unsuccessful simulations and $G\left(x_{i}\right)$ is the performance function as defined by Equation 3.

$$
I\left(x_{I}\right)=\left\{\begin{array}{l}
1 \text { if } G\left(x_{i}\right) \geq 0 \\
0 \text { if } G\left(x_{i}\right)<0
\end{array}\right\}
$$

The number of independent random samples $N$ is obtained from the joint probability distribution function (PDF) of the $x_{1}, x_{2} \ldots x_{N}$ for each independent variable. Thus the probability of failure can be calculated, and the reliability index $\beta$.

\subsection{Selection Of The Load Combination Schemes}

Holický et al. (2015) [6] suggested that the formulation of combination schemes for the various design standards represents a critical element of the design's reliability basis. The design scheme is linked to the respective combinations (permanent, accidental, variable action, etc.). Various design schemes in both EC3 and SANS 10162-1 can be derived from Equation 4.

$$
\sum \gamma_{G, i} g_{k, i}+\gamma_{Q, 1} \psi_{0,1} q_{k, 1}+\sum_{i>1} \gamma_{Q, 1} \psi_{0, i} q_{k, i}
$$

The partial factors for permanent $\left(g_{k, i}\right)$ and variable $\left(q_{k, i}\right)$ actions are denoted by the symbols $\gamma_{G, i}$ and $\gamma_{Q, i}$. The combination factors are denoted by $\psi_{0, i}$. Turkstra's rule for the assessment of the combination of actions states that the effect of the combination of actions is based on the leading or dominant action not being reduced but rather the accompanying nondominant actions being reduced by combination factors $\psi_{0, i} \leq 1$. The combination scheme for multivariable actions needs to maintain a minimum level of reliability across a range of load ratios where either variable or permanent loads dominate. A combination of Turkstra's rule and calibration to local conditions (Milford, 1988) [11] is used to achieve a consistent reliability level. The design value for the load effect $E_{d}$ is obtained using characteristic value $\left(G_{k}, Q_{k}, W_{k}\right)$ multiplied by their respective partial factors $\left(\gamma_{G}, \gamma_{Q}, \gamma_{W}\right)$ and reduction factors. The combination schemes are derived from Equation 4 . Under the load effect's variable action, $E_{d}$ would not easily compare the characteristic values. Therefore, the quantities related to the characteristic values $\left(G_{k}, Q_{k}, W_{k}\right)$ are connected using variable action ratios. Mahachi (2019) [9] used statistical moment parameters to represent the wind load ratio $\alpha$ and the live load ratio $\zeta$, as defined by Equations 5 and 6, respectively. 


$$
\begin{aligned}
& \alpha=\frac{w_{k}}{G_{k}+Q_{k}+w_{k}} \\
& \xi=\frac{Q_{k}}{G_{k}+Q_{k}}
\end{aligned}
$$

The design value $E_{d}$ can, therefore, be expressed as Equation 7 where $\mathrm{G}_{\mathrm{k}}$ is the characteristic value for the permanent loads, $Q_{k}$ is the characteristic value of the imposed loads and $\mathrm{W}_{\mathrm{k}}$ the characteristic value of the wind load.

$$
E_{d}=\frac{G}{G_{k}} \zeta(1-\alpha)+\frac{Q}{Q_{k}}(1-\zeta)(1-\alpha)+\frac{w}{w_{k}} \alpha
$$

\subsection{Selection Of Model Resistance Value}

A laterally unsupported class 1 beam subjected to bending ( 457 x 191 x 74 I Beam) and a class 1 pin ended compression member ( 203 x 203 x 46 H Column) subjected to an axial load were used to determine the moment resistance of each member. These two members were selected to be representative examples of a steel member in flexure and compression

\subsubsection{SANS Beam}

The critical elastic moment resistance (Mcr) of a laterally unsupported member under bending can be determined by Equation 8. Furthermore, a slenderness check must be done according to Equation 9 to determine the moment resistance of a laterally unsupported member subject to bending

$$
\begin{aligned}
& M_{c r}=\frac{\omega_{2} \pi}{K L} \sqrt{E I_{y} G J+\left(\frac{\pi E}{K L}\right)^{2} I_{y} C_{w}} \\
& M_{r}= \begin{cases}1.15 \phi M_{p}\left(1-0.28 M_{p} / M_{c r}\right) \leq \phi M_{p} & \text { if } M_{c r}>0.67 M_{p} \\
\phi M_{c r} & \text { if } M_{c r} \leq 0.67 M_{p}\end{cases}
\end{aligned}
$$

In the above equation, Mcr is the critical elastic moment of an unbraced length, $\mathrm{Cw}$ is the torsional constant, $\mathrm{K}$ is the

effective length factor, $\mathrm{L}$ is the effective length of the simply supported unbraced member, ${ }^{\omega_{2}}$ is the coefficient to account for increased moment resistance of a laterally unsupported segment, and $\mathrm{Mp}$ is the plastic moment.

\subsubsection{SANS Column}

For a pin-pin-ended member under axial compression, the design compressive resistance can be calculated using Equation 10.

$$
\begin{aligned}
& C_{r}=\phi A f_{y}\left(1+\lambda^{2 n}\right)^{-\frac{1}{n}} \\
& \qquad \lambda=\frac{K l}{r} \sqrt{\left(\frac{f_{y}}{\pi^{2} E}\right)} ; n=1.34 \text { (for doubly symmetric welded plate }=2.24 \text { ) }
\end{aligned}
$$

\subsubsection{EC3 Beam}

The moment resistance for laterally unsupported members, lateral-torsional buckling must be checked so that the moment resistance can be determined by Equation 11.

$$
M_{b}, R_{d}=\frac{X_{L T} \beta w W_{p l . y} f_{y}}{\gamma_{M 1}}
$$




$$
\begin{aligned}
& X_{L T}=\frac{1}{\Phi_{L T}+\sqrt{\Phi^{2}{ }_{L T}-\lambda^{2}{ }_{L T}}} \text {, but } X_{L T} \leq 1 \\
& \Phi_{L T}=0.5\left[1+\alpha_{L T}\left(\lambda_{L T}-0.2\right)+\lambda_{L T}^{2}\right]
\end{aligned}
$$

(11c)

$$
\lambda_{L T}=\sqrt{\frac{W_{p l . y} f_{y}}{M_{c r}}}
$$

Wpl.y is the plastic section modulus, which is the same as the SANS 10162-1 section modulus denoted by Zpl and is expressed as a basic random variable with the probability density functions shown in Table 1 . $\beta \mathrm{w}$ is equal to 1 for class 1 and 2 sections, and XLT is the capacity reduction factor for lateral-torsional buckling. The lateral-torsional imperfection factor $\alpha \mathrm{LT}$ is determined by the type of buckling curve where $\mathrm{a} 0=0.13, \mathrm{a}=0.21, \mathrm{~b}=0.34, \mathrm{c}=0.49$ and $\mathrm{d}=0.76$. E is Young's modulus, $r$ is the radius of gyration, fy is the yield strength, and $\gamma_{M 1}$ is the partial factor for resistance of members.

\subsubsection{EC3 Column}

For a member under axial compression, the compression resistance can be calculated using Equation 12, where $\chi$ is the reduction factor used for the relevant buckling mode.

$$
\begin{aligned}
& N_{b}, R_{d}=\frac{\chi A f_{y}}{\gamma_{M 1}} \\
& \chi=\frac{1}{\Phi+\sqrt{\Phi^{2}-\lambda^{2}}}, \quad \text { but } \chi \leq 1 \\
& \Phi=0.5\left[1+\alpha(\lambda-0.2)+\lambda^{2}\right] \\
& \lambda=\sqrt{\frac{A f_{y}}{N_{c r}}}
\end{aligned}
$$

Calculating the compressive resistance of EC3 is not as straight forward as that of SANS 10162-1. Both standards calculate the yield stress reduced by reduction factors; EC3 also has buckling curves (a, b, c, d) and an imperfection factor assigned to represent a column curve. The reduction factor for EC3 is, as stated in clause 5.5.1.2 of the Eurocode as well as Equation 12 above.

\subsection{Defining and Evaluating the Performance Function}

The variables that make up the resistance $R$ have been detailed in Table 1 . They have been determined through a combination of theoretical models describing a steel column and beam (Ellingwood (1980)) [4], and others have been determined deterministically. The distributions of the variables have been verified through the probabilistic model code (JCSS, 2002) [7], some of the variables are considered to be random variables having normal $(N)$ distributions, and others are deterministic (Det.).

The statistical moment parameters of the load effect $E_{d}$ used to calculate the probability of failure are obtained from Holicky (2015) [6] and Kemp et al. (1998) [8] and are presented in table 2. Having received the characteristic values that make up the vector $\mathbf{x}$, the limit state function $G(\mathbf{x})=g\left(x_{1}, x_{2}, x_{3}, \ldots, x_{n}\right)$ is modified and expressed as Equation 13 for beams subjected to bending and for columns subjected to axial compression.

$$
G(\mathbf{x})=P\left(G_{k}+Q_{k}+W_{k}\right) \geq R_{d}
$$


The probability of failure given by Equation 2 is modified and expressed as Equation 14 and 15 for SANS 10162-1 flexural beam elements and Equation 16 for the column.

$P_{f}=P\left[\left(G_{k}+Q_{k}+W_{k}\right) \geq 1.15 \phi M_{p}\left(1-\frac{0.28 M_{p}}{\frac{1.75 \pi}{L} \sqrt{E I_{y} G J+\left(\frac{\pi E}{L}\right)^{2} I_{y} C_{w}}}\right]\right]$

$P_{f}=P\left[\left(G_{k}+Q_{k}+W_{k}\right) \geq \phi \frac{1.75 \pi}{L} \sqrt{E I_{y} G J+\left(\frac{\pi E}{L}\right)^{2} I_{y} C_{w}}\right]$

$P_{f}=P\left[\left(G_{k}+Q_{k}+W_{k}\right) \geq \phi A f_{y}\left(1+\left(\frac{K h}{r} \sqrt{\frac{f_{y}}{\pi^{2} E}}\right)^{2.68}\right)^{-\frac{1}{1.34}}\right]$

Equation 2 is modified and expressed as Equation 17 for the EC3 flexural beam and Equation 18 for the column.

$$
\begin{aligned}
& P_{f}=P\left[\left(G_{k}+Q_{k}+W_{k}\right) \geq X_{L T} W_{p l . y} f_{y}\left(\frac{1}{\gamma_{M 1}}\right)\right] \\
& P_{f}=P\left[\left(\left(G_{k}+Q_{k}+W_{k}\right) \geq \chi\left(\frac{1}{\gamma_{M 1}}\right) A f_{y}\right]\right.
\end{aligned}
$$

The reliability index $\beta$ is then determined by substituting each equation (from 14 to 18) individually into Equation 19 . For the column, the " $K$ " value will be equal to 1 for a pin-pin-ended column. The effective length is denoted by "h" to not confuse the effective length of the beam "L".

$$
\beta=-\Phi^{-1}\left(P_{f}\right)
$$

Equation 19 is then evaluated using computer software MATLAB and an Excel spreadsheet to determine the reliability levels of a laterally unsupported steel beam subjected to bending and a steel column subjected to axial compression. In this

\begin{tabular}{|c|c|c|c|c|c|c|c|c|c|}
\hline $\begin{array}{l}\mathbf{N} \\
\mathbf{0}\end{array}$ & $\begin{array}{c}\text { Categor } \\
\text { y of } \\
\text { variabl } \\
\text { es }\end{array}$ & Variable Description & $\underset{X}{\text { Symb }}$ & $\begin{array}{l}\text { Uni } \\
t\end{array}$ & $\begin{array}{l}\text { Distributi } \\
\text { on }\end{array}$ & $\begin{array}{c}\text { Characteri } \\
\text { stic value } \\
X_{k}\end{array}$ & $\underset{\mu X}{\text { Mean }}$ & $\begin{array}{l}\text { Std. dev } \\
\sigma X\end{array}$ & $\begin{array}{l}\text { C.O.V } \\
V . x .\end{array}$ \\
\hline 1 & & Modulus of elasticity & E & $\mathrm{MPa}$ & Det. & 200 & 200 & 0 & - \\
\hline 2 & & Steel strength & fy & $\begin{array}{l}\mathrm{M} \\
\mathrm{Pa}\end{array}$ & Det. & 350 & - & - & - \\
\hline 3 & & $\begin{array}{l}\text { St. Venant Torsional } \\
\text { Constant }\end{array}$ & $J$ & $\begin{array}{l}\mathrm{m} \\
\mathrm{m} \\
4\end{array}$ & Det. & 527 & 527 & 0 & - \\
\hline 4 & Materials & Second Moment of Inertia & $I y$ & $\begin{array}{l}\mathrm{m} \\
\mathrm{m}\end{array}$ & Det. & 16.7 & 16.7 & 0 & - \\
\hline
\end{tabular}
research, no eccentricity will be considered.

Table 1: Probabilistic models of basic variables of a steel beam and column. 


\begin{tabular}{|c|c|c|c|c|c|c|c|c|c|}
\hline & & & & & & & & & \\
\hline & & & & 4 & & & & & \\
\hline 5 & & $\begin{array}{l}\text { Warping Torsional } \\
\text { Constant }\end{array}$ & $C w$ & $\begin{array}{l}\mathrm{m} \\
\mathrm{m}^{6}\end{array}$ & Det. & 820 & 820 & 0 & - \\
\hline 6 & & Shear Modulus & G & $\begin{array}{l}\mathrm{M} \\
\mathrm{Pa}\end{array}$ & Det. & 77 & 77 & 0 & - \\
\hline 7 & & Radius of gyration & $r$ & $\begin{array}{l}\mathrm{m} \\
\mathrm{m}\end{array}$ & Det. & 88.1 & 88.1 & 0 & - \\
\hline 8 & & Span of the Beam & $L$ & $\mathrm{~m}$ & $\mathrm{~N}$ & Varies & Varies & Varies & - \\
\hline 9 & Geometry & Section Modulus Beam & W & $\begin{array}{c}\mathrm{mm} \\
3 \\
\end{array}$ & Det. & 1660 & 1660 & 0 & - \\
\hline $\begin{array}{l}1 \\
0\end{array}$ & & Column Length/Height & $h$ & $\mathrm{~m}$ & $\mathrm{~N}$ & Varies & Varies & Varies & - \\
\hline $\begin{array}{l}1 \\
1\end{array}$ & & $\begin{array}{l}\text { Cross Sectional area } \\
\text { Column }\end{array}$ & $A$ & $\mathrm{~m} 2$ & Det. & 5.88 & 5.88 & 0 & - \\
\hline
\end{tabular}

Key: Det. $=$ Deterministic $; \mathrm{N}=$ Normal Distribution

Table 2: Load Statistic of the basic variables describing the load effect

\begin{tabular}{|l|c|c|c|}
\hline $\begin{array}{l}\text { Variable x (Load } \\
\text { Type) }\end{array}$ & Distribution & $\begin{array}{c}\text { Mean/Characteristic } \\
\text { value }\end{array}$ & $\begin{array}{c}\text { Coefficient of } \\
\text { Variation }\end{array}$ \\
\hline Permeant load (G) & Normal & 1.05 & 0.1 \\
\hline Live load - Lifetime & Gumbel Type I & 0.71 & 0.24 \\
\hline $\begin{array}{l}\text { Live Load (Office } \\
\text { floor)-Point in time }\end{array}$ & Gumbel Type I & 0.68 & 0.25 \\
\hline Wind lifetime max & Gumbel Type I & 0.70 & 0.35 \\
\hline
\end{tabular}

\section{Findings and Analysis}

\subsection{Comparison of SANS 10162-1 \& EC3 Beam Reliability Levels}

Selected practical load combinations are used in a probabilistic comparison of a laterally unsupported beam in bending. The resulting reliability index $\beta$ is plotted as a function of the live load ratio for any given length "L". The live load ratio $\zeta$, is incremented by a value of 0.1 , between 0 and 1 , and plotted on the $\mathrm{x}$-axis with the $\beta$ values on the y-axis. The SANS beam and EC3 beam's reliability index is compared at critical wind load ratios and plotted on a reliability index graph against live load ratios. 


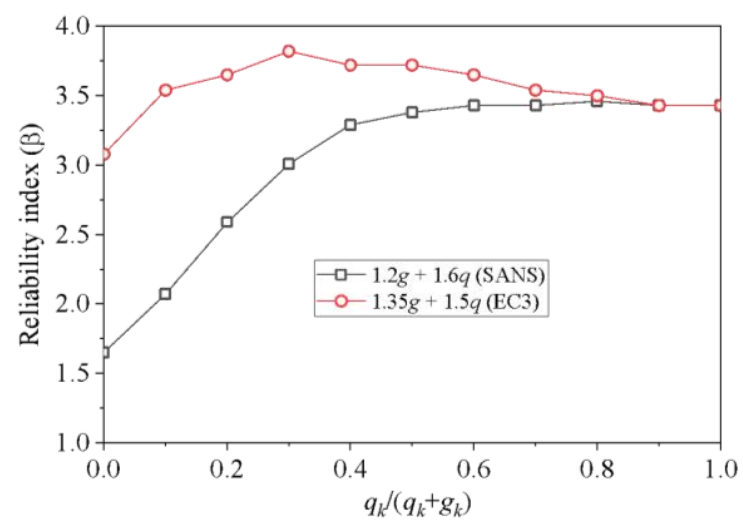

Figure 1. Comparison of EC3 and SANS 10162-1 Beam Reliability Indices (when $\alpha=0$ )

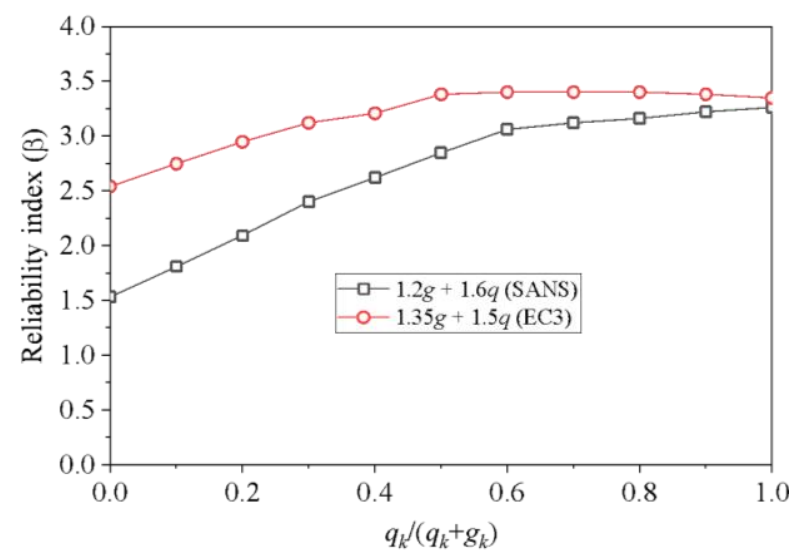

Figure 2. Comparison of EC3 and SANS 10162-1 Beam Reliability Indices (when $\alpha=0.6$ ).

Figure 1 provides a comparison of the SANS $\left(1.2 \mathrm{G}_{\mathrm{k}}+1.6 \mathrm{Q}_{\mathrm{k}}\right)$ and Eurocode $\left(1.35 \mathrm{G}_{\mathrm{k}}+1.5 \mathrm{Q}_{\mathrm{k}}\right)$ load combination schemes. The SANS curve produces reliability index values below those of the Eurocode curve; however, as the live load ratio increases, the reliability index values begin to converge. It should be noted that although Eurocode produces higher reliability levels at low live load ratios and within the practical live load range, the difference in reliability indices is small. In the practical live load ratio range of $0.5-0.8$, the difference goes from 0.2 down to 0 . Both standards comply with the SANS 10160 (2018) [13] target value where $\beta_{t}=3.0$ for moderate consequences of failure (RC2). But for all live load ratios, the reliability of the Eurocode is less than $\beta_{t}=3.8$. When the wind load ratio $\alpha=0.6$, the SANS $\left(1.2 \mathrm{G}_{\mathrm{k}}+1.6 \mathrm{Q}_{\mathrm{k}}\right)$ and Eurocode $\left(1.35 \mathrm{G}_{\mathrm{k}}+1.5 \mathrm{Q}_{\mathrm{k}}\right)$ load combination schemes are compared. SANS produces low-reliability levels for live load ratios between 0-0.6. In contrast, the Eurocode produces reliability indices higher than the SANS set of results, and for practical live load ratios, the reliability index is above the SANS target value of 3.0. The reliability levels of the Eurocode seem to remain constant at a high wind load.

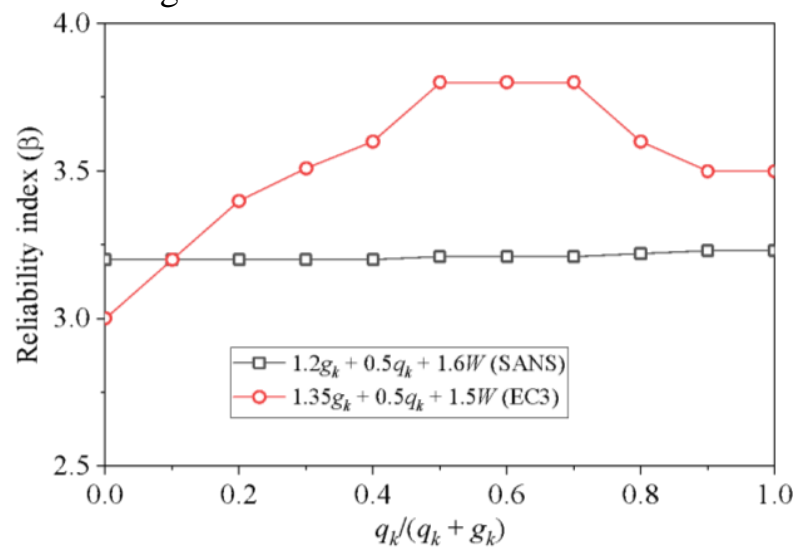

Figure 3. Comparison of EC3 and SANS 10162-1 Beam Reliability Indices (when $\alpha=0.6$ ).

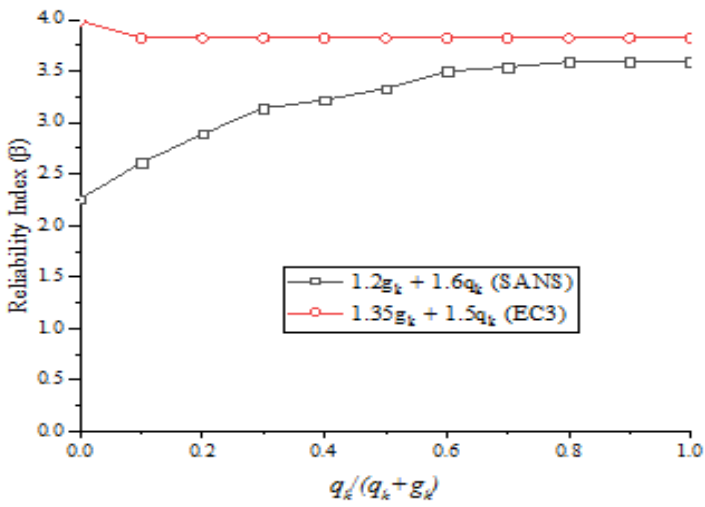

Figure 4. Comparison of EC3 and SANS 10162-1 Column Reliability Indices (when $\alpha=0$ ).

When the wind load ratio $\alpha=0.6$, the SANS $\left(1.2 \mathrm{G}_{\mathrm{k}}+0.5 \mathrm{Q}_{\mathrm{k}}+1.6 \mathrm{~W}_{\mathrm{k}}\right)$ and Eurocode $\left(1.35 \mathrm{G}_{\mathrm{k}}+1.05 \mathrm{Q}_{\mathrm{k}}+1.5 \mathrm{~W}_{\mathrm{k}}\right)$ load combination schemes are compared. SANS produces a linear set of reliability levels that remain consistent at a value of 3.2. This is only marginally less than the Eurocode reliability values, which are higher. The Eurocode values predict a range closer to the target value of 3.8 and vary to 3.6 at a live load ratio of 0.8 . That is a difference of 0.6 at the highest value of the Eurocode reliability index.

\subsection{Comparison of SANS 10162-1 \& EC3 Column Reliability Levels}

Similarly, for the columns, the SANS column and EC3 column's reliability index are compared at critical wind load 
ratios and plotted as previously seen in the previous section. Figure 4 above provides a comparison of the SANS $\left(1.2 \mathrm{G}_{\mathrm{k}}+\right.$ $\left.1.6 \mathrm{Q}_{\mathrm{k}}\right)$ and Eurocode $\left(1.35 \mathrm{G}_{\mathrm{k}}+1.5 \mathrm{Q}_{\mathrm{k}}\right)$ load combination schemes. EC3 produces high levels of reliability. Reliability indices are linear and at a constant value of 3.8, which aligns with the target reliability index required by the Eurocode $\beta \mathrm{t}=3.8$ for moderate consequences of failure (RC2). SANS has lower reliability indices, but at the practical live load ratio range (0.50.8 ), the difference in reliability levels of 0.3 is small. The large difference in reliability, though, is at low-reliability indices.

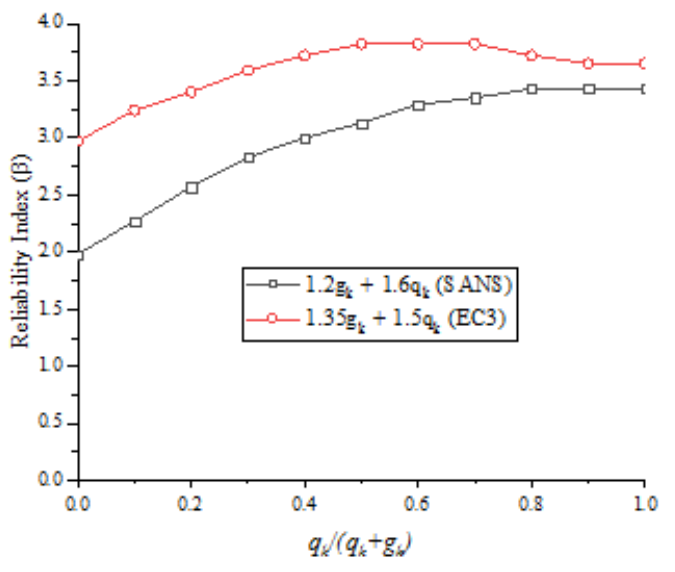

Figure 5. Comparison of EC3 and SANS 10162-1 Column Reliability Indices (when $\alpha=0.6$ ).

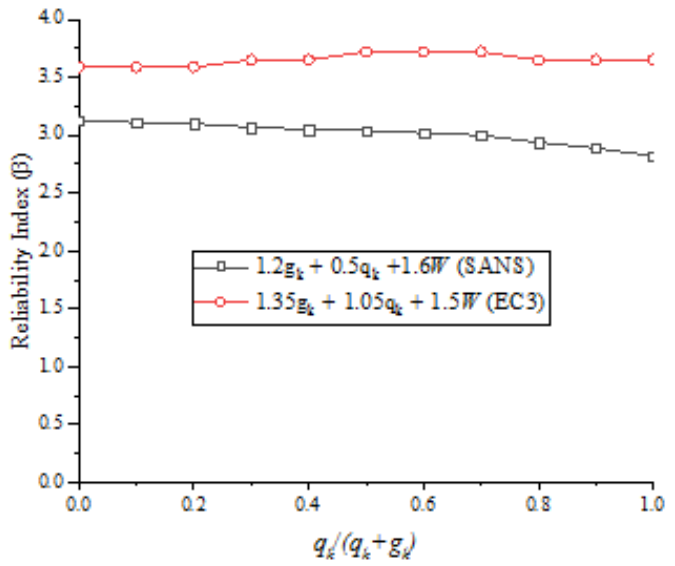

Figure 6. Comparison of EC3 and SANS 10162-1 Column Reliability Indices (when $\alpha=0.6$ ).

When the wind load ratio $\alpha=0.6$, the SANS $\left(1.2 \mathrm{G}_{\mathrm{k}}+1.6 \mathrm{Q}_{\mathrm{k}}\right)$ and Eurocode $\left(1.35 \mathrm{G}_{\mathrm{k}}+1.5 \mathrm{Q}_{\mathrm{k}}\right)$ load combination schemes are compared. SANS produces lower reliability levels than the Eurocode for the entire range of live load ratios $(0-1)$. The reliability levels of the Eurocode are consistent and are above the SANS target value. From live load ratios of 0.4, the SANS curve produces reliability indices above the target value of 3.0. When the wind load ratio $\alpha=0.6$, the $S A N S\left(1.2 \mathrm{G}_{\mathrm{k}}+0.5 \mathrm{Q}_{\mathrm{k}}\right.$ $\left.+1.6 \mathrm{~W}_{\mathrm{k}}\right)$ and Eurocode $\left(1.35 \mathrm{G}_{\mathrm{k}}+1.05 \mathrm{Q}_{\mathrm{k}}+1.5 \mathrm{~W}_{\mathrm{k}}\right)$ load combination schemes are compared. SANS produces a linear set of reliability levels that remain consistent at a value of 3.2 to a low of 2.9. This is significantly less than the Eurocode reliability values, which are higher by 0.5 .

\section{[1] 4. CONCLUSION}

This paper presented a reliability-based comparison of Eurocode $3 \&$ SANS 10162-1. The South African target reliability index being $\beta_{t}=3.0$ for moderate consequences of failure (RC2), and the Eurocode target value of $\beta_{t}=3.8$. Although the EC 3 reliability levels were higher, the difference can be attributed to the partial safety factors and the conservative basis of the Eurocode. The results in this study found that the compression member would yield higher reliability indices than the member in flexural bending, which is in line with what was observed by Ellingwood \& Galambos (1982) [3], where a target value of 3.0 was suggested for beams in flexure and a target value of 3.5 for columns. The modification of the wind load combination for SANS 10160 (2018) [13] to the updated Eurocode wind load prediction model (Botha, 2016) [1], results in the reliability indices of SANS 10162-1 being closer to the EC3 reliability index by a value of 0.6 units (in the case of a beam and 0.5 units for a column). A minimum target reliability index of 3.0 is still maintained, and for the entire range of live load ratios (0-1), the reliability index $\beta=3.2$. These reliability indices show the efficiency in the modified partial factor for the wind load.

\section{[2] 5. REFERENCES}

[3] Botha, J., 2016. Probabilistic Models of Design Wind Loads in South Africa. Stellenbosch University: Unpublished doctoral dissertation.

[4] EC3, 2002. Eurocode 3: Basis for Structural Steel. Brussels: European Committee for Standardisation (C.E.N.).

[5] Ellingwood, B. \& Galambos, T., 1982. Probability-Based Criteria for Structural Design. Structural Safety, Issue 1, pp. $15-26$.

[6] Ellingwood, B., Galambos, T., J.G, M. \& Cornell, C., 1980. Development of a Probability Based Load Criterion for American National Standard A58.. In: N.B.S. Special Publication 577. Washington, DC: National Bureau of Standards. 
[7] EN1990, 2002. Basis of structural design. Brussels: European Committee for Standardisation (C.E.N.).

[8] Holický, M., Diamantidis, D. \& Sykora, M., 2015. Determination of Target Safety for Structures. Vancouver, 12th International Conference on Applications of Statistics and Probability in Civil Engineering.

[9] JCSS, 2002. JCSS Probabilistic Model Code. [Online]Availableat:https://www.jcss-lc.org/jcss-probabilistic-modelcode/[Accessed June 2020].

[10] Kemp, A., Mahachi, J. \& Milford, R., 1998. Comparisons of international loading codes and options for South Africa. Midrand, South Africa, South Africa National Conference on Loading. SAICE \& SAISC.

[11] Mahachi, J., 2019. Adaptation or Adoption of Eurocode Steel Design: A Comparison with SouthAfricanStandard.Johannesburg:(University of Johannesburg).

[12] Mallin, M., 2019. Do we realise that buildings are beyond the scope of our codes in many cases. Journal of the South African Institution of Civil Engineering, 27(4), pp. 14-17.

[13] Milford, R., 1988. Target Safety and SABS 0160 load factors. The Civil Engineer, 30(10), pp. 475-481.

[14] Retief, J., Dithinde, M. \& Viljoen, C., 2011. Reliability basis for adopting Eurocodes as South African standards.. Zurich, The 11th International Conference on Applications of Statistics and Probability in Civil Engineering.

[15] SANS10160, 2018. SANS 10160: Basis of structural design actions for buildings and industrial structures. Pretoria: SABS Standards Division..

[16] SANS10162-1, 2005. SANS 10162-1: 2011 The Structural Use of Steel. Part 1: Limit-State Design of Hot-rolled Steelwork.. Pretoria: SABS Standards Division.

\section{[17] 6. NOMENCLATURE}

\section{Ed}

$E\{-\}$

$G$

$G k, j$

$Q$

$Q k$

$\beta$

$\beta t$

$\gamma G$

$\gamma Q$

$\gamma W$

G

$h$

$I$

design value of effect of actions

function defining the effect of actions

permanent action

characteristic value of permanent action, $\mathrm{j}$

variable action

characteristic value of a variable action

reliability index

target safety index

combination factor for variable action

partial factor for the permanent load

partial factor for the imposed load

partial factor for the wind load

\section{SANS 10162-1}

A

$\mathrm{Cr}$

$C w$

E

fy
Cross-sectional area

Compressive resistance of a member

Warping torsional constant

Young's Modulus of elasticity

Yield strength of steel

Shear Modulus of steel

Height of section

Moment of inertia 


\section{$J$ \\ K \\ $L$ \\ $\mathrm{Mcr}$ \\ $M p$ \\ $\mathrm{Mr}$ \\ $r$ \\ $\mathrm{Zpl}$ \\ $\lambda$ \\ $\varnothing$}

$\omega_{2}$

EC3

$C_{1}$

$M_{R D}$

$N_{c r}$

$N_{R D}$

$W_{p l}$

$\alpha$

$\Phi$

$X L T$
St. Vernant torsion constant

Effective length factor

Length of member

Critical elastic moment for lateral torsional buckling

Plastic moment

Factored moment resistance

Radius of gyration

Plastic section modulus of a steel section

Non-dimensional slenderness ratio in column formula

Capacity reduction resistance factor

Coefficient to account for increased moment resistance of a laterally supported segment subjected to a moment gradient

Modification factor to account for increased moment resistance of a laterally unsupported segment subjected to a moment gradient forces

Design value for resistance to bending

Elastic critical force for the relevant buckling mode

Design value for resistance to axial forces

Plastic section modulus of a steel section

Imperfection factor

Value to determine the reduction factor

Capacity reduction factor for lateral torsional buckling 